\title{
SESTET: a Spatially-Explicit Stream Temperature model based on Equilibrium Temperature
}

Luca Carraro $^{1,2}$, Marco Toffolon ${ }^{3}$, Andrea Rinaldo $^{1,4}$, Enrico Bertuzzo $0^{5, *}$

${ }^{1}$ Laboratory of Ecohydrology, Swiss Federal Institute of Technology in Lausanne (EPFL), Lausanne, Switzerland

${ }^{2}$ Aquatic Ecology Group, Swiss Federal Institute of Aquatic Science and Technology (Eawag), Dübendorf, Switzerland ${ }^{3}$ Department of Civil, Environmental and Mechanical Engineering, University of Trento, Trento, Italy

${ }^{4}$ Department of Civil, Environmental and Architectural Engineering, University of Padua, Padua, Italy

${ }^{5}$ Department of Environmental Sciences, Informatics and Statistics, University of Venice Ca' Foscari, Venice, Italy

* Corresponding author: enrico.bertuzzo@unive.it

Running title: SESTET: spatially-explicit stream temperature model

Keywords: River temperature | Thermal refugia | Neutral stability algorithm | Soil temperature interpolation | Thermal inversion | Adaptive Metropolis algorithm

Acknowledgements: LC, AR and EB acknowledge the support provided by the Swiss National Science Foundation through the Sinergia project CRSII3_147649: “Temperature driven emergence of Proliferative Kidney Disease in salmonid fish - role of ecology, evolution and immunology for aquatic diseases in riverine landscapes". The authors wish to thank Bernard Sperandio for his help in collecting stream temperature data.

Data Availability Statement: The data that support the findings of this study are openly available in figshare at http://doi.org/10.6084/m9.figshare.8035388, reference number 8035388.

This article has been accepted for publication and undergone full peer review but has not been through the copyediting, typesetting, pagination and proofreading process which may lead to differences between this version and the Version of Record. Please cite this article as doi: 10.1002/hyp.13591 


\section{Abstract}

Stream-water temperature is a key variable controlling chemical, biological and ecological processes in freshwater environments. Most models focus on a single river cross-section; however, temperature gradients along stretches and tributaries of a river network are crucial to assess ecohydrological features such as, e.g., aquatic species suitability, growth and feeding rates, or disease transmission. We propose SESTET, a deterministic, spatially-explicit stream temperature model for a whole river network, based on water and energy budgets at a reach scale and requiring only commonly available spatially distributed datasets, such as morphology and air temperature, as input. Heat exchange processes at the air-water interface are modelled via the widely used equilibrium temperature concept, while effects of network structure are accounted for through advective heat fluxes. A case study was conducted on the prealpine Wigger river (Switzerland), where water temperatures have been measured in the period 2014-2018 at eleven spatially distributed locations. Results show the advantages of accounting for water and energy budgets at the reach scale for the entire river network, compared to simpler, lumped formulations. Because our approach fundamentally relies on spatially distributed air temperature fields, adequate spatial interpolation techniques that account for the effects of both elevation and thermal inversion in air temperature are key to a successful application of the model. SESTET allows the assessment of the magnitude of the various components of the heat budget at the reach scale and the derivation of reliable estimates of spatial gradients of mean daily stream temperatures for the whole catchment based on a limited number of conveniently located (namely, spanning the largest possible elevation range) measuring stations. Moreover, accounting for mixing processes and advective fluxes through the river network allows one to trust regionalized values of the parameters controlling the relationship between equilibrium and air temperature, a key feature to generalize the model to data-scarce catchments.

\section{Introduction}

Stream-water temperature is a crucial variable for the study of aquatic ecosystems, as it controls several chemical, biological and ecological processes, such as nutrient consumption rate, photosynthesis, respiration, oxygen solubility and codiment suspension [Webb et al., 2008; Ducharne, 2008]. Stream temperature heavily impacts the metabolic balance of fluvial ecosystems [Yvon-Durocher et al., 2010; Demars et al., 2011] and determines the metabolic rates of organisms, their distribution along the river network and their interaction with other species [Allan and Castillo, 2007]. Organisms require specific temperature ranges to survive and proliferate, and the excess of critical temperature thresholds might have lethal effects [Lee and Rinne, 1980; Nielsen et al., 1994; Eaton et al., 1995]. Moreover, temperature exerts an effect on species geographical distribution [Parmesan and Yohe, 2003]. For instance, ectothermic animals are remarkably impacted by water temperature, which strongly influences their rates of biochemical reaction, development and growth [Angilletta et al., 2002; Jonsson and Jonsson, 2009]. Stream temperature significantly impacts also the ecology of freshwater salmonids, keystone freshwater species for their ecological, recreational and commercial value. Indeed, temperature represents one of the abiotic variables influencing habitat suitability, although it is argued that other factors such as water depth, current, substrate and cover might be more important than temperature in controlling 
the distribution and abundance of salmonids [Heggenes, 1990; Armstrong et al., 2003]. However, temperature plays a major role in determining mobility patterns of fish: salmon and trout perform behavioural thermoregulation by occupying cooler upstream reaches when temperatures rise above their upper tolerances [Theurer et al., 1985; Berman and Quinn, 1991]. Moreover, warm water temperatures are responsible for the shrinkage in seasonal migration patterns [Berman and Quinn, 1991], and for the fragmentation of watershed-wide fish populations by isolating suitable thermal habitats [Matthews and Zimmerman, 1990; Ebersole et al., 2001]. These zones, sheltering biotic communities from thermal disturbances, are referred to as thermal refugia [Sedell et al., 1990; Torgersen et al., 1999]. Temperature variations related to climate change can have devastating repercussions on salmonid populations [Hari et al., 2006; McCullough et al., 2009]. For instance, water temperature is a major driver of the highly lethal Proliferative Kidney Disease (PKD) in salmonids [Okamura et al., 2011; Carraro et al., 2017].

A good understanding of the river thermal processes and of the natural and anthropogenic factors controlling water temperature fluctuations is thus fundamental. Stream temperature is controlled by a number of factors, subdivided by Caissie [2006] into four main groups: topography (such as stream aspect, latitude, altitude, slope, riparian vegetation), discharge (water volume, turbulence, inflows and outflows), atmospheric conditions (solar radiation, air temperature, wind speed, humidity, rainfall, snow, evaporation) and influence of the streambed (conduction, hyporheic exchange, groundwater input). The long history of stream temperature models [Sverdrup et al., 1942; Morse, 1970; Smith, 1972] focused on isolating those few key factors that, depending on the spatial and temporal scales of interest, have the most significant impact on temperature dynamics. Models can essentially be divided into two main categories: statistical models and deterministic models, although the transition between the two is not well definite.

Statistical models mainly consist in linear or logistic regression between water temperature at a river cross section and few relevant predictors, among which air temperature plays a major role [Benyahya et al., 2007; Arismendi et al., 2014]. Despite their simplicity, these models show good performances in reproducing temperature variability at long time scales, such as weekly, monthly or seasonal [e.g., Piccolroaz et al., 2016]. For this reason, they are often employed in practical applications although their use is questionable for conditions outside the calibration range. In ungauged catchments, regression models are often employed to determine the impact of human activities and climate change on the environment [Gallice et al., 2015]. However, such models typically focus only on yearly aggregated temperature metrics, and therefore they are unsuited to predict the annual cycle of stream temperature, which is a key factor cum rolling biochemical and ecological processes, such as the distribution of fish and other riverine species [Heggenes et al., 1999].

When temperature variability at shorter time scales (say hourly or daily) is relevant, stochastic or deterministic models might be preferred. Stochastic models [e.g., Caissie et al., 2001] belong to the group of statistical models, but unlike regression models they take into account the auto-correlation of the water temperature time series. Deterministic models instead consider all the relevant hydrological and heat exchange processes characterizing the energy budget [e.g., Sinokrot and Stefan, 1993]. In the middle, hybrid models retain certain features of the deterministic models while introducing a data-driven approach [e.g., Toffolon and Piccolroaz, 2015].

A relevant component of the heat budget is the total heat flux exchanged at the water surface, which subsumes the processes of solar radiation, net long-wave radiation, evaporation and convection [Caissie, 2006]. A number of 
deterministic, process-based approaches that extensively characterize all of these heat fluxes exist [Cao et al., 2016; Dugdale et al., 2017]. These models are generally coupled with spatially-explicit hydrological routines and produce estimates of stream temperature at fine spatial (hundreds of meters) and temporal (sub-daily) scales. However, such approaches are rather data-demanding, as they typically require comprehensive datasets on climatological (such as precipitation, wind speed, humidity, solar radiation) and environmental (e.g. land cover, riparian shading, canopy height) variables. In order to simplify the expression of the heat flux at the air-water interface and reduce the number of input variables required, many other deterministic models successfully exploit the so-called equilibrium temperature concept [Edinger et al., 1968; Caissie et al., 2005], according to which the total heat flux is proportional to the difference between water temperature and the equilibrium temperature, which can be formulated as a function of air temperature and possibly other predictors. The drawback of this approach is that the regression coefficients typically reflect local conditions and hence they allow reliable predictions through time, but they would result in poor performances when used to predict stream temperatures at some distance from the site where they were calibrated.

The existing equilibrium temperature-based and hybrid stream temperature models span different degrees of spatial detail and physical representativeness (see e.g. the approaches proposed by Gallice et al. [2015]; Comola et al. [2015]; Toffolon and Piccolroaz [2015] to account for advection processes), although most of these models predict water temperatures only at given river's cross-sections (typically, the outlet). Conversely, the prediction of spatial gradients of water temperature at a network scale is critical for models aimed at ecohydrological applications, such as assessing spatial niche variability for aquatic species and potential effects in propagation of diseases. In order to achieve this goal, we here propose SESTET (Spatially-Explicit Stream Temperature model based on Equilibrium Temperature), a deterministic temperature model for a whole river network, based on the application of water and energy budgets at a reach scale and on the equilibrium temperature concept to express local heat transfer with the atmosphere. In particular, the spatial variability of water temperature dynamics is constrained into the processes of heat transport and mixing, while a spatially constant parametrization of the equation linking air and equilibrium temperature is maintained. An asset of the model is that it is based on easily accessible datasets such as river morphology and air temperature. In fact, extended datasets on upland shading and riparian zone conditions are hardly accessible and would limit a widespread model application. Essentially, our approach aims at reconciling the degree of physical and spatial detail characteristic of process-based models [Dugdale et al., 2017] with the simplicity of the methods based un the equilibrium temperature concept, while maintaining the capability of predicting stream temperature across space. Another strong point of our model is its computational efficiency, which enables parameter estimation via iterative or Bayesian approaches. Our model is tested on a case study, the prealpine Swiss river Wigger, where water temperatures have been collected at 11 different locations in the period 2014-2018.

The paper is organized as follows: in the following section, the SESTET model is formulated in a general form and compared to traditional non-advective models [Caissie et al., 2005; Bustillo et al., 2014]. Subsequently, the study area and dataset are presented and a number of assumptions and parametrizations specific to the analyzed case study are introduced. The following results and discussion section focuses first on a comparison of the predictive performance of SESTET versus non-advective models; second, it analyses relevant output from SESTET, such as spatio-temporal evolution of heat fluxes at the reach scale and spatial gradients of stream temperature across the catchment; third, 
it shows the crucial role played by spatial interpolation of air temperatures in our model's predictive performance. Finally, the main conclusions of this work are outlined.

\section{The model}

\subsection{Formulation of the SESTET model}

Stream temperature models typically comprise two equations describing the water and heat budgets, and several models based on different assumptions have been proposed in past and recent literature. In our approach, we couple a spatial description of the river network with water and energy budgets at the reach level. Let us consider a river network discretized into $N_{r}$ reaches of suitable length $L_{i}, i=1, \ldots, N_{r}$ (Fig. 1). Reaches' lengths and number can be arbitrarily tuned to obtain the desired degree of spatial resolution. For the sake of clarity, all symbols and respective dimensions used here and in the following are listed in Table S1 (Supporting Information). Reaches are assumed to be well-mixed, i.e. the water temperature $T_{i}$ at time $t$ is uniform along each reach $i$, implying that within-reach temperature spatial gradients are neglected. The connectivity between reaches is expressed via an adjacency matrix $\mathbf{W}$ with entries $w_{j i}=1$ if reach $j$ drains directly into reach $i$ and null otherwise. At any reach $i$, the water budget reads

$$
\frac{\mathrm{d} V_{i}}{\mathrm{~d} t}=\sum_{j=1}^{N_{r}} w_{j i} Q_{j}+Q_{i}^{L}-Q_{i},
$$

where $V_{i}$ is the volume of water in reach $i, Q_{i}$ is the water discharge flowing out of reach $i$, and $Q_{i}^{L}$ the discharge contribution from the subcatchment directly draining into reach $i$. The energy budget reads

$$
\frac{\mathrm{d}}{\mathrm{d} t}\left(\rho c_{p} V_{i} T_{i}\right)=\sum_{j=1}^{N_{r}} w_{j i} \phi_{j}+\phi_{i}^{L}-\phi_{i}+\phi_{i}^{n a},
$$

where $\rho$ is the density of water, $c_{p}$ the specific heat of water at constant pressure, $\phi_{i}=\rho c_{p} T_{i} Q_{i}$ the heat flux flowing through the exit cross-section of reach $i, \phi_{i}^{L}=\rho c_{p} T_{i}^{L} Q_{i}^{L}$ the heat flux related to the water flux $Q_{i}^{L}$, with $T_{i}^{L}$ being the temperature of $Q_{i}^{L}$, and $\phi_{i}^{n a}$ the overall non-advective heat flux at reach $i . T_{i}^{L}$ can be seen as the weighted average temperature of $Q_{i}^{L}$, as this flux is typically made up of different contributions possibly characterized by different temperatures (e.g., groundwater, surface runoff, snowmelt). Non-advective heat fluxes can be expressed as $\phi_{i}^{n a}=\phi_{i}^{a w}+\phi_{i}^{s b}$, where $\phi_{i}^{a w}$ represents the heat flux at the air-water interface, while $\phi_{i}^{s b}$ is the heat exchanged with the streambed. The river-atmosphere term $\phi_{i}^{a w}$ includes sensible (or conductive) heat, latent (or evaporative) heat, net solar (short-wave) radiation, atmospheric and emitted (long-wave) radiations. By using the equilibrium temperature concept, the net exchange can conveniently be expressed as $\phi_{i}^{a w}=k_{i}^{\prime} A_{i}^{a w}\left(T_{i}^{e q}-T_{i}\right)$, where $A_{i}^{a w}$ is the area of the air-water interface, $T_{i}^{e q}$ is the equilibrium temperature and $k_{i}^{\prime}$ is a heat exchange coefficient. Hence, one has

$$
\frac{\phi_{i}^{a w}}{\rho c_{p}}=k_{i} A_{i}^{a w}\left(T_{i}^{e q}-T_{i}\right),
$$


where $k_{i}=k_{i}^{\prime} /\left(\rho c_{p}\right)$ (hereafter termed heat exchange velocity) represents the velocity of the heat exchange process between air and water.

The streambed heat flux $\phi_{i}^{s b}$ comprises the conductive heat flux across the streambed and the friction dissipation [Sinokrot and Stefan, 1993]. These terms are often of minor importance in the energy budget [Evans et al., 1998], although contrasting evidence on the role of heat exchanges at the streambed exists (e.g. see Arrigoni et al. [2008] on the effect of hyporheic discharge on stream temperature). In the Supporting Information we show how it is possible to include a term accounting for streambed conductive heat flux within the SESTET framework as a function of soil thermal conductivity. On the other hand, the friction heat flux can be readily expressed via the already introduced variables without further parametrizations:

$$
\frac{\phi_{i}^{s b}}{\rho c_{p}}=\frac{\rho g \Delta z_{i} \overline{Q_{i}}}{\rho c_{p}}=\frac{g s_{i} L_{i} \overline{Q_{i}}}{c_{p}}
$$

where $g$ is the gravity acceleration, $\Delta z_{i}=s_{i} L_{i}$ is the difference in elevation between the highest and lowest points of the reach (with $s_{i}$ being the average slope of the reach), and $\overline{Q_{i}}=\left(\sum_{j=1}^{N_{r}} w_{j i} Q_{j}+Q_{i}\right) / 2$ is the average discharge flowing through the reach $i$ [Comola et al., 2015].

By combining Eqs. (1), (2), (3) and (4) and assuming the product $\rho c_{p}$ as constant, one gathers (details are provided in the Supporting Information):

$$
\frac{\mathrm{d} T_{i}}{\mathrm{~d} t}=\frac{1}{V_{i}}\left[\sum_{j=1}^{N_{r}} w_{j i}\left(T_{j}-T_{i}\right) Q_{j}+\left(T_{i}^{L}-T_{i}\right) Q_{i}^{L}+k_{i} A_{i}^{a w w}\left(T_{i}^{e q}-T_{i}\right)+\frac{g s_{i} L_{i} \overline{Q_{i}}}{c_{p}}\right] .
$$

The general form of the SESTET model is a coupled (via the term $T_{j}-T_{i}$ ) system of ordinary differential equations constituted by $N_{r}$ Eqs. (5), one for each reach into which the river network is partitioned. This model will be compared with a number of simplified formulations in the following section.

To model the equilibrium temperature $T_{i}^{e q}$, we adopt a general formulation that assumes a linear relationship with air temperature $T_{i}^{A}$, with an additional sinusoidal term with yearly period acting as a proxy of solar radiation:

$$
T_{i}^{e q}=a T_{i}^{A}+b+c \cos \left[\frac{2 \pi}{t_{Y}}\left(t-t_{\max }\right)\right]
$$

where $t_{Y}$ is equal to one year; $t_{Y}$ and $t_{\max }$ are expressed in the same unit as $t$; and $a, b, c$ and $t_{\max }$ are parameters requiring calibration. These parameters subsume the local features characterizing the air-water heat exchanges (e.g., shading factor, wind speed, air humidity etc.) and hence they typically need to be calibrated separately for each crosssection of the river [Caissie et al., 2005]. As a result, stream temperature models based on equilibrium temperature are usually unable to predict temperature gradients across a watershed. Here we claim that, by explicitly considering the role of the diverse contributions to the heat budget, it is possible to use regionalized (i.e. constant in space) values for these parameters while maintaining the accurate prediction capabilities of the model. The formulation (6) resembles that of Bustillo et al. [2014], with the difference that in this case the time of sinusoidal peak is an additional free parameter. This choice aims at better capturing the delay between the peak of solar radiation and that of water temperature. An analogous formulation is used in the air2stream model by Toffolon and Piccolroaz [2015]. 


\subsection{Non-advective models}

The set of simplified models hereafter presented is derived from Eq. (5) by properly specifying further assumptions for the hydrothermal processes taking place in the reach.

A common simplification (see e.g. Caissie et al. [2005]; Bustillo et al. [2014]) is to assume that advective terms (i.e. those proportional to water discharge $Q$ and temperature gradients) are negligible compared to non-advective ones. Following this assumption, the SESTET (S) model is reduced to a purely local (L) model:

$$
\frac{\mathrm{d} T_{i}}{\mathrm{~d} t}=\frac{k_{i} A_{i}^{a w}}{V_{i}}\left(T_{i}^{e q}-T_{i}\right) .
$$

Even if this local model neglects advective fluxes, it does partially account for hydrological variability in the term $A_{i}^{a z w} / V_{i}$, which models how the air-water interface area varies with respect to the volume for changing water depth. If one further assumes that such variability has a negligible impact on non-advective heat fluxes, the flat (F) model is derived:

$$
\frac{\mathrm{d} T_{i}}{\mathrm{~d} t}=\widehat{k}_{i}\left(T_{i}^{e q}-T_{i}\right)
$$

where the heat exchange rate $\widehat{k}_{i}$ is introduced. Finally, by further assuming $\mathrm{d} T_{i} / \mathrm{d} t=0$, one gathers the equilibrium (E) model

$$
T_{i}=T_{i}^{e q}
$$

This approximation implies that the time scale for the adaptation of water temperature to the external forcing is much shorter than the time time step of the model [e.g., Toffolon and Piccolroaz, 2015], which is one day in the case study here presented.

\section{Case study}

\subsection{Study area and dataset}

The river Wigger (see Fig. 2), located in the Swiss plateau, is a tributary of the river Aare and has a length of $48.11 \mathrm{~km}$. .. ains a watershed of $382.4 \mathrm{~km}^{2}$ which has an elevation range comprised between 396 and $1409 \mathrm{~m}$ a.s.l., at the Mount Napf. Water temperature has been measured since June 2014 in 10 sites via HOBO TidbiT ${ }^{\circledR}$ v2 data loggers. An additional temperature gauge (site \#11 in Fig. 2a) was added in September 2015. Two loggers, recording data at 15minutes intervals, were deployed per each site. Air temperature data from 20 neighbouring stations were provided by MeteoSwiss. Mean daily discharges and water depths are measured by the Swiss Federal Office for the Environment (FOEN) in Zofingen (corresponding to site \#1 in Fig. 2a).

Mean daily measured water temperatures are available from Jun 28, 2014 to Jun 30, 2018 at sites \#1 to \#10; from Sep 28, 2015 to Oct 4, 2016 and from Sep 6, 2017 to Jun 30, 2018 at site \#11. The lack of data between October 2016 and September 2017 for this site is due to the loss of both loggers after a large sediment transport event.

The morphology of the watershed (derived as in Carraro et al. [2017]) was obtained from a 25-m resolution digital terrain model, while the river network was extracted by means of the Taudem method [Tarboton et al., 1991]. Flow 
directions were determined by following steepest descent paths. Pixels were considered to belong to the channeled portion of the landscape if their drained area was greater than or equal to $0.5 \mathrm{~km}^{2}$. In order to subdivide the catchment into units where reasonably constant local morphological conditions apply, stream reaches longer than $5 \mathrm{~km}$ were split into equally long stretches. In total, the river network was divided into 166 reaches (of mean length $1.57 \mathrm{~km}$ ) hierarchically arranged according to the network connectivity, each of them associated with a cluster of pixels directly draining into the reach. Spatial interpolation of air and soil temperatures (see following section) is performed on the centroids of such pixel clusters. Morphological features of reaches and respective subcatchments are provided in Table S2 and Fig. S1 (Supporting Information).

\subsection{Hydraulic characterization}

River's cross-sections are approximated as rectangular, with width $B$ constant along the reach and much greater than river depth $D$. Therefore, the water volume at a reach $i$ reads $V_{i}=L_{i} B_{i} D_{i}$, where $L_{i}$ is the reach length. Assuming that propagation of flow perturbations is much faster than the daily time scale used in the model and that rainfall, and the ensuing runoff generation processes, are not strongly heterogeneous when integrated at daily time scale (both assumptions are reasonable for this case study but likely applicable to any catchments at least up to $10^{3} \mathrm{~km}^{2}$ ), discharge at any time $t$ can be assumed to be proportional to contributing area $A$ [Rodriguez-Iturbe and Rinaldo, 2001], i.e. $Q_{j}(t)=\beta_{1, j i} Q_{i}(t)$, where the morphological coefficient $\beta_{1, j i}=A_{j} / A_{i}$ is introduced. Therefore, from equation (1) follows that

$$
Q_{i}^{L}=\frac{\mathrm{d} V_{i}}{\mathrm{~d} t}+\left(1-\sum_{j=1}^{N_{r}} w_{j i} \beta_{1, j i}\right) Q_{i}=\frac{\mathrm{d} V_{i}}{\mathrm{~d} t}+\beta_{2, i} Q_{i}
$$

Finally, a third morphological coefficient $\beta_{3, i}=1-\beta_{2, i} / 2$ can be introduced to express $\overline{Q_{i}}=\beta_{3, i} Q_{i}$.

To infer river depth in every reach we exploit the widely-used hydraulic geometry scaling relationships in the downstream direction, first introduced by Leopold and Maddock [1953]. One such relationship assumes that, for a fixed discharge frequency, river depth scales in the downstream direction as $D_{i} \sim Q_{i}^{\delta}$. Although the exponent $\delta$ is typically found to be close to 0.4 over a wide range of natural streams, it is kept as a free calibration parameter in this case study. Owing to the assumed proportionality between discharge and contributing area, water depths at any

h can thus be expressed as $D_{i}=\beta_{1, i o}^{\delta} D_{o}$, where subscript $o$ identifies a cross-section (e.g. the outlet) where a discharge time series and an at-a-site stage-discharge relationship are available.

Finally, the heat exchange velocity, $k_{i}$, can be made site-specific by expressing it as a function of stream temperature [Bustillo et al., 2014], although it will hereafter be considered constant for the sake of simplicity. By inserting Eqs. (10) and the relationships linking $Q_{i}, D_{i}$, and $V_{i}$ to $Q_{o}$ and $D_{o}$ into Eq. (5), one finally gathers the complete SESTET model used in this application:

$$
\frac{\mathrm{d} T_{i}}{\mathrm{~d} t}=\frac{\beta_{1, i o}^{1-\delta}}{L_{i} B_{i}} \frac{Q_{o}}{D_{o}}\left[\sum_{j=1}^{N_{r}} w_{j i} \beta_{1, j i}\left(T_{j}-T_{i}\right)+\left(\beta_{2, i}+\frac{L_{i} B_{i}}{\beta_{1, i o}^{1-\delta} Q_{o}} \frac{\mathrm{d} D_{o}}{\mathrm{~d} t}\right)\left(T_{i}^{L}-T_{i}\right)+\beta_{3, i} \frac{g s_{i} L_{i}}{c_{p}}\right]+\frac{k}{\beta_{1, i o}^{\delta} D_{o}}\left(T_{i}^{e q}-T_{i}\right) .
$$

In addition to air temperature, which controls $T^{e q}$, the application of Eq. (11) requires several other types of input data. First, a morphological characterization of the catchment must be available. The extraction of the river 
network from a digital elevation model [Tarboton et al., 1991] readily allows for the computation of coefficients $\beta_{1, j i}$ $\beta_{2, i}, \beta_{3, i}$ (which solely depend on the drainage area), the adjacency matrix $\mathbf{W}$, reach lengths and slopes. Reach widths can instead be estimated via in situ measurements, aerial images (as in the presented case study; details are provided in the Supporting Information) or, failing that, width-discharge relationships [Leopold and Maddock, 1953]. Second, a time series of discharge $Q_{o}$ and water depth $D_{o}$ at a convenient cross-section of the river enables the derivation of water fluxes at all reaches thanks to the assumption of proportionality between $Q$ and $A$. Third, other spatially heterogeneous environmental variables are required for the parametrization of $T_{i}^{L}$, which, for instance, can be expressed as a function of soil temperature. The hydrological characteristics of a river, such as the presence of natural or artificial lakes or the role exerted by snowmelt, have a major impact on the thermal regime [e.g., Piccolroaz et al., 2016; Arora et al., 2018]. In Eq. (11), such a type of information can be embedded by conveniently specifying the spatial pattern of $T_{i}^{L}$. The specific characterization of these input data for the case study at hand is detailed in the following.

\subsection{Interpolation of spatial data}

Air temperature. Key to any successful model of water temperatures is the full exploitation of the data available from field measurements. One issue is obviously the best use of spatial data for air temperature. Spatial fields of daily mean, maximum and minimum air temperatures, together with precipitation, are available for the whole Europe thanks to the E-OBS dataset [Cornes et al., 2018]. However, such estimates are gridded at a 25-km resolution, which makes them too coarse for the current application. A spatial interpolation of point-based air temperature data is therefore required. This can be performed via a variety of methods, including kriging, inverse-distance weighting, Gaussian filters and 2-dimensional splines [Myers, 1994; Stahl et al., 2006]. However, these methods are typically conceived for flat and homogeneous terrains [Dodson and Marks, 1997], while in mountainous regions the relationship between elevation and air temperature must be accounted for prior to performing a spatial interpolation. Lapse rates (i.e. the rates at which air temperature changes following an increase in altitude) range between $-9.8^{\circ} \mathrm{C}$ $\mathrm{km}^{-1}$ (dry adiabatic lapse rate) and $-4.0^{\circ} \mathrm{C} \mathrm{km}-1$ (dry saturated lapse rate), with $-6.5^{\circ} \mathrm{C} \mathrm{km}^{-1}$ being a typical value for the global mean environmental lapse rate [Barry and Chorley, 2009]. Especially in winter, the typical pattern

ecreasing air temperature with increasing altitude can be altered by temperature inversions or cold air ponding [Csanady, 1974]. This phenomenon might hinder the achievement of great accuracies in air temperature prediction in small but topographically complex areas. As shown by Jarvis and Stuart [2001], empirical techniques of interpolation accounting for known autocorrelation in the temperature data can prove more efficient than the reliance on the selection of guiding variables or sophisticated spatial interpolation algorithms.

Stemming from these considerations, the approach here proposed does not specify an a priori value for the lapse rate, but rather evaluates mean air temperature $T_{p}^{A}(t)$ during day $t$ at the prediction point $p$ as a weighted average of temperatures $T_{i}^{A}(t)$ recorded at $N_{A}$ measuring stations:

$$
T_{p}^{A}(t)=\frac{\sum_{i=1}^{N_{A}} Y_{i p} T_{i}^{A}(t)}{\sum_{i=1}^{N_{A}} Y_{i p}}
$$


where

$$
Y_{i p}=E_{i p}^{-\alpha_{E}} \Delta Z_{i p}^{-\alpha_{Z}} .
$$

Our approach resembles that of Thornton et al. [1997], inasmuch as the relationship between air temperature and elevation changes for each day of prediction. Weights $Y_{i p}$ are function of both the Euclidean distance $E_{i p}$ (expressed in $\mathrm{km}$ ) between the measuring site $i$ and the prediction point $p$ and their absolute difference in altitude $\Delta Z_{i p}=\left|Z_{i}-Z_{p}\right|$ (expressed in $\mathrm{m}$ ). $\alpha_{E}$ and $\alpha_{Z}$ are positive parameters that were calibrated via grid search with a Leave-One-Out-CrossValidation technique [Hastie et al., 2001] on the daily air temperature time series measured in the period 2014-2018 at the 20 MeteoSwiss stations (Fig. 2a). Tested values for both parameters were the natural numbers in the interval [0; 10]. The prediction error was aggregated over all stations and expressed as root mean square error (RMSE). The best-fit parameters $\alpha_{E}=2, \alpha_{Z}=2$ attained RMSE $=1.36{ }^{\circ} \mathrm{C}$.

For comparison, the same calibration procedure was applied to spatially interpolated air temperatures obtained with the Neutral Stability Algorithm (NSA) proposed by Dodson and Marks [1997], a method with specified lapse rate. NSA converts air temperature data to sea-level potential temperatures (namely, the temperature attained by a fluid adiabatically brought to a pressure of $10^{5} \mathrm{~Pa}$ ), spatially interpolates sea-level potential temperatures via inverse distance weighting, and then uses the inverse of the potential temperature function to retrieve air temperatures at the sought elevation. This algorithm requires two parameters: the lapse rate and a reference sea-level air temperature value. RMSE values obtained for the NSA algorithm displayed in Fig. S2 (Supporting Information) were obtained by setting these two parameters to $-6.5{ }^{\circ} \mathrm{C} \mathrm{km}^{-1}$ and $20^{\circ} \mathrm{C}$, respectively. Other values (within meaningful ranges) were tested but did not yield any improvement in the performance. The aggregated RMSE obtained with the NSA method was $\mathrm{RMSE}=2.09^{\circ} \mathrm{C}$.

Lateral inflow temperature. Since the Wigger is not regulated or substantially impacted by snowmelt, in this application the water temperature of the lateral flow $T_{i}^{L}$ is assumed to be equal to the soil temperature at 1-m depth $T_{i}^{S}$. Soil temperature data were obtained for the set of eight MeteoSwiss stations shown in Fig. $2 \mathrm{~b}$. At the same stations, air temperatures are also recorded. Most time series of soil temperatures spanned periods comprised between years 1970 and 2000. Daily values of soil temperatures at 1-m depth were obtained by linear regression on moving-averaged air temperatures. Calibration was performed by aggregating data over all stations. The linear regression coefficients, as well as the time window for the moving average, were kept constant for all stations. Values of the time window explored were the natural numbers in the range $[1 ; 80]$ days. For each of these values, a linear regression between soil temperatures and moving-averaged air temperatures was performed. We chose the model whose aggregated root mean square error was the lowest. The calibrated regression reads $T_{i}^{S}=0.76 T_{i}^{A, M A}+3.65$, where $T_{i}^{A, M A}$ is the moving average of $T_{i}^{A}$ with a time window equal to 53 days. The corresponding RMSE is $1.24^{\circ} \mathrm{C}$. Fig. S3 (Supporting Information) displays the goodness of fit achieved by the regression model for each of the eight soil temperature stations. 


\subsection{Model calibration and performance}

The SESTET model and the three non-advective models (see summary in Table 1) are calibrated on the whole available dataset by means of an adaptive Metropolis algorithm [Haario et al., 2001], where the likelihood $\mathcal{L}$ is calculated by assuming independent and identically distributed Gaussian errors between daily observed and modelled temperatures. This analysis is aimed at selecting the best model formulation and assessing parameter identifiability using all the information available. The performance of the four models is assessed via the Deviance Information Criterion [Spiegelhalter et al., 2002; Gelman et al., 2004]

$$
\mathrm{DIC}=\mathrm{E}[\mathcal{D}]+\frac{1}{2} \operatorname{Var}[\mathcal{D}]
$$

where $\mathcal{D}=-2 \ln \mathcal{L}$ is the deviance; $\mathrm{E}[\mathcal{D}]$ and $\operatorname{Var}[\mathcal{D}]$ its expected value and variance, respectively. Lower DIC scores indicate better performance. Because the absolute values of DIC are not significant, model comparison is actually performed through $\triangle \mathrm{DIC}$, i.e. the differences of DIC scores with respect to the minimum DIC achieved by the best model.

In an additional set of calibration exercises we test the predictive performance of the models in both space and time by subdividing data into a calibration and validation subsets in three different ways. The first (subset I) excludes from the calibration dataset the full-length time series at sites \#2, \#6, \#9, in addition to the last fifth of the time series at all other sites (i.e., from Sep 10, 2017); the second (subset II) excludes from calibration the time series at sites \#1, \#5, \#8, in addition to the first fifth of the time series at all other sites (i.e., until Apr 16, 2015); the third (subset III), specifically aimed at assessing the model's performance in time, excludes from calibration the last two fifths of all time series (i.e., from Nov 22, 2016). Hence, calibration subset I, II and III comprise 56\%, 58\% and $60 \%$ of the whole dataset, respectively. As in this predictive analysis we are only interested in deriving the best-fit parameters rather than the complete posterior distribution, parameter estimation on subsets I, II and III is performed by minimizing the root mean square error on the calibration subset $\mathrm{RMSE}_{\mathrm{c}}$ via particle swarm optimization [Kennedy and Eberhart, 1995]. Model performance is evaluated by means of the Akaike Information Criterion (AIC) for the calibration dataset and the root mean square error for the validation subset (RMSE $\mathrm{v})$. Up to an additive constant that only depends on the number of observations $N_{o b s}$ and not on the model, AIC reads

$$
\mathrm{AIC}=2 N_{p}+N_{o b s} \ln \left(\mathrm{RMSE}_{\mathrm{c}}{ }^{2}\right)
$$

Also in this case, model comparison is performed through $\triangle \mathrm{AIC}$.

In order to assess the sensitivity of our model to changes in the spatial interpolation of air temperature, we ran a final calibration of the model on the full dataset by using air temperature data obtained with the NSA method. Calibration was performed by minimizing the aggregated RMSE by means of the particle swarm optimization algorithm.

In all cases, in order to lose memory of the initial condition, all model runs start from Jun 1, 2014 with an initial stream temperature of $10{ }^{\circ} \mathrm{C}$ at all stretches. Hence, the warm-up period lasts 27 days. 


\section{Results and discussion}

\subsection{Comparison of model performance and role of parameters}

Table 2 summarizes results for all models and calibration runs. The SESTET (S) model attains the best performances with regards to both calibration on the full dataset and on subsets I, II and III. Remarkably, model S also achieves the best performances in the validation period (lowest $\mathrm{RMSE}_{\mathrm{V}}$ for subsets I, II and III), which excludes overfitting issues. In particular, as reported in Table 3, model S proves particularly capable of capturing stream temperature dynamics at the most upstream site (\#11), where, when air temperatures are interpolated via Eq. (12), RMSE values are always lower than $1{ }^{\circ} \mathrm{C}$ regardless of the calibration set, while all non-advective models attain RMSE greater than $1.2{ }^{\circ} \mathrm{C}$. The improved performance of model S with respect to the validation subset III suggests that SESTET is capable of efficiently predict stream temperatures beyond the observation time window and to possibly mitigate the inaccuracies of regression models based on air temperature in terms of stream temperature forecasting [Arismendi et al., 2014]. However, we acknowledge that time series longer than the ones available for this case study would be required in order to investigate this aspect in higher detail.

Among non-advective models, the simple formulation based on instantaneous equilibrium between air and water temperature (E) performs more poorly than the models that explicitly account for stream temperature temporal dynamics (namely L and F, see Table 2). In particular, the model that assumes that air-water heat exchange is independent of water depth (F) attains slightly lower RMSE values than model L for all calibration attempts, despite containing a lower number of parameters. Indeed, best-fit values of parameter $\delta$ (Fig. 3, Table S3 in Supporting Information), expressing how water depth varies along stream direction, are close to 0 for model L (as well as for model S) and all calibration subsets. Note that assuming $\delta=0$ would reduce model $\mathrm{L}$ to a model akin to $\mathrm{F}$, with the difference that the coefficient that multiplies the difference between equilibrium and stream temperatures does not depend on space but does depend on time.

Posterior distributions for $\delta$ (see Fig. 3) for models $S$ and L are non-informative, i.e. they span the whole tested range [0; 1]. However, a preference is observed for values lower than $\delta=0.4$ proposed by Leopold and Maddock [1953], further corroborated by the above-mentioned occurrence of best-fit values close to 0 . Such low values for $\delta$ cumradict the evidence that water depth does increase along the downstream direction. This apparently counterintuitive behaviour results from the fact that daily averaged temperature is not sensitive to water depth in small streams [Toffolon and Piccolroaz, 2015]. Hence, since calibration was solely conducted against stream temperature data, our models are not aimed at predicting spatial variation in hydrological variables such as water depth. Moreover, the good performance obtained by models that predict high water depths in the upstream reaches might indicate that the actual heat exchange velocities in this part of the catchment are higher than those predicted by the spatiallyconstant parameter $k$ adopted in the explored model formulation. In this perspective, the adoption of spatiallyvarying heat exchange velocities (e.g. by expressing them as linear functions of stream temperature at-a-site, as proposed by Bustillo et al. [2014]) might be beneficial in isolating the effects of thermodynamics ( $k_{i}$ term in Eq. (5)) and hydrology $\left(A_{i}^{a w} / V_{i}\right)$ in the air-water heat exchange process. However, preliminary analyses (not shown) did not show any sensible improvement in the model's performance when the heat exchange velocity was made temperature 
dependent.

For all best-fit models, peaks of the sinusoidal component of the equilibrium temperature relationship (represented by $t_{\max }$ ) occur after the summer solstice (see Fig. 2), when incoming solar radiation reaches its peak. A possible explanation for the lag between these two peaks can be attributed to the thermal inertia of the water body, which causes delayed responses of stream temperature to the external forcing. Interestingly, best-fit values for $t_{\max }$ in model S are around Jul 1 - Jul 16, while for the other models they are further delayed (around Jul 29 - Aug 7), implying that part of the delay between the radiation peak and the calibrated $t_{m a x}$ for traditional (non-spatial) models is to be attributed to the neglect of advective heat fluxes in the heat budget formulation. Furthermore, the posterior distribution for $t_{\max }$ for model $\mathrm{S}$ is wider than those obtained for non-advective models, as it also spans the late spring period. This observation is also confirmed by the fact that values of parameter $c$ (the mid-amplitude of the sinusoidal term of $T_{e q}$ ) tend to be smaller for model $\mathrm{S}$ than for the other models. Finally, calibrated values of the heat exchange velocity $k$ seldom exceed $1 \mathrm{~m} \mathrm{~d}^{-1}$ for both models $\mathrm{S}$ and $\mathrm{L}$, in agreement with previous findings [Bustillo et al., 2014].

Results from the best-fit simulation of model S (hereafter termed $\mathrm{S}^{*}$ ) calibrated on the full dataset is analyzed in detail in the following. An excerpt of the performance of model $S^{*}$ for year 2016 across all sampling sites is presented in Fig. 4.

\subsection{Analysis of the SESTET model}

Estimation of heat fluxes. SESTET allows for the computation of the diverse components of the heat budget Eq. (2). As shown in Fig. 5ab, the friction heat flux appears negligible both in downstream and upstream reaches. The heat flux at the air-water interface $\phi_{i}^{a w}$ is generally positive in winter and spring and negative in summer and autumn, reflecting changes in the sign of $T_{i}^{e q}-T_{i}$. Advective terms such as the along-stream heat flux $\sum_{j=1}^{N_{r}} w_{j i} \phi_{j}-\phi_{i}$ and the lateral heat flux $\phi_{i}^{L}$ follow the opposite trend, being mostly negative during the first half of the year while switching to positive or approximating zero in the second semester. The mechanisms underlying this behaviour can be reconstructed by comparing the signals of equilibrium, soil and stream temperatures (Fig. $5 \mathrm{~cd}$ ). The sign of the along-stream heat flux is controlled by the difference in stream temperature among contiguous reaches, i.e. if $j$ is

only reach draining into $i$, then the along-stream heat flux will be positive if and only if $T_{j}>T_{i}$. If lateral and friction heat fluxes are negligible, the latter condition is likely to occur when $T_{i}>T_{i}^{e q}$ : in fact, if both $T_{j}>T_{i}$ and $T_{i}^{e q}>T_{i}, \mathrm{~d} T_{i} / \mathrm{d} t$ would be positive, thereby $T_{i}$ would increase until one of the two heat fluxes eventually changes sign. Note that such a relationship can be altered when the lateral heat flux is taken into account. At the downstream site \#1 (Fig. 5a), where lateral flux plays a relatively minor role in the heat budget because $Q_{i}^{L} \ll Q_{i}$, air-water and along-stream fluxes tend to have opposite signs (which is the case in $83.3 \%$ of the days of the examined period). Note that, owing to the large values of water discharge at the downstream reaches, the along-stream heat flux can have an absolute magnitude comparable to that of the air-water flux even if the difference in temperature between reach $\# 1$ and the reaches that drain into it is tiny (in $51.8 \%$ of the days of the examined period-mostly during the second semester- the temperature of the largest reach upstream of \#1 is higher than that of \#1; the median of the positive temperature differences is $0.014{ }^{\circ} \mathrm{C}$ ). As a result, stream temperature at the downstream reaches is poorly impacted 
by soil temperature, while its trend closely follows that of equilibrium temperature (Fig. 5c). At the upstream site \#11

(Fig. 5b), the along-stream flux is positive in $21.5 \%$ of the days, implying that in most of the times reach \#11 is warmer than its upstream reaches, as expected in portions of the catchment with stronger elevational gradient. In this reach, air-water heat flux is mostly contrasted by lateral flux, whose sign is controlled by the difference $T_{i}^{S}-T_{i}$. $T_{i}$ tends to be confined between the lower bound $T_{i}^{S}$ and the upper bound $T_{i}^{e q}$ in winter and spring, while the two bounds are flipped in summer and autumn. This is mainly due to the delay in the soil temperature signal with respect to that of equilibrium temperature, as reported in Fig. 5d. This panel also shows that, in the upstream reaches, stream temperature mostly follows the trend of soil temperature during the first half of the year, while the decline in stream temperature observed in the second semester is mainly governed by equilibrium temperature.

Stream temperature trends with respect to upstream contributions, equilibrium and soil temperatures for the whole river network are displayed in Fig. 6. In the first semester, equilibrium temperature is generally higher than stream temperature (Fig. 6c), while soil temperature tends to be colder than stream temperature (Fig. 6e), resulting in a spatial pattern of increasing stream temperature in the downstream direction (Fig. 6a). Such tendencies are reversed in the second semester, when $T_{i}^{e q}<T_{i}<T_{i}^{S}$ (Fig. 6df). As a result, low-elevation headwaters, being primarily controlled by lateral inflow, tend to be warmer than downstream reaches (Fig. 6b). In high-elevation areas instead (southernmost region of the catchment), the increasing trend of stream temperature in the downstream direction is preserved. Note that the lighter colors of the main river course in Figs. 6cd with respect to the headwaters indicate that equilibrium temperature is the main driver of stream temperature in these downstream reaches. Conversely, the opposite shading of Figs. 6ef indicates that soil temperature mainly controls stream temperature only in the headwaters.

Spatial gradients of water and air temperature. Owing to its capability of adequately reproducing temperature dynamics in the upstream reaches, SESTET enables an assessment of spatial gradients of stream temperature, particularly as a function of elevation. Indeed, due to the scarcity of high elevation measuring sites in this case study, the evaluation of elevation effects on stream temperature based only on observed temperature values would be difficult. Note that this issue might also be relevant to other datasets, since the positioning of temperature loggers in high-elevation reaches might pose technical challenges (e.g. transport of large sediments, ephemerality).

For each day of the observation period, linear regressions were performed on modelled $\left(\mathrm{S}^{*}\right)$ stream temperatures and interpolated (via Eq. (12)) air temperatures against elevation. Results are reported in Fig. 7. As expected, variations of stream temperature with elevation are milder than those of air temperature, both in terms of intercept (which represents sea-level temperature, Fig. 7a) and slope (corresponding to lapse rate, Fig. 7b). Lapse rates are mostly negative both for air and water temperature, but thermal inversion might occur in winter: for water temperature, lapse rates are positive in $24.1 \%$ of the days between October and March, and $0 \%$ (no occurrences) between April and September; as for air temperatures, these percentages are $25.9 \%$ and $0.02 \%$ respectively. The median value of air temperature lapse rate is $-5.3^{\circ} \mathrm{C} \mathrm{km}^{-1}$, in agreement with previous findings [Barry and Chorley, 2009]; for water temperature, the median lapse rate equals $-3.1^{\circ} \mathrm{C} \mathrm{km}^{-1}$. 


\subsection{Influence of air temperature estimation}

If the neutral stability algorithm is used in lieu of Eq. (12) to perform the spatial interpolation of air temperatures, the performance of all models (except E) worsens noticeably (see Table 2). This downturn is mainly to be attributed to the poor result obtained for the upstream site $\left(\# 11\right.$, where RMSE $=1.416{ }^{\circ} \mathrm{C}-$ see Table 3$)$. Indeed, the NSA method proved particularly inadequate to reproduce air temperatures at higher elevations (see Fig. S2), where winter thermal inversion hinders the performance of spatial interpolation methods with fixed lapse rate.

\section{Conclusions}

Stream temperature is a critical factor for riverine ecosystems, owing to the control it exerts on metabolic rates of organisms, aquatic species' niche suitability, and spread and incidence of infectious diseases. This work proposed SESTET, a spatially-explicit, deterministic stream temperature model capable of evaluating within-river gradients of mean daily temperature and therefore suitable for ecological and ecohydrological applications. The originality of our approach, compared to existing temperature models, consists in embedding a simple but robust hydrological characterization of the river network into an energy budget expressed at a reach level. This enables the evaluation of reliable estimates of spatio-temporal stream temperature dynamics across the entire catchment based on a limited number of conveniently located (namely, spanning the largest possible elevation range) measuring stations and on a restricted amount of input data (chiefly, a digital elevation model of the catchment and air temperatures spatially interpolated over the region), thereby making SESTET an appropriate tool for applications where more extensive datasets are lacking. Results showed how considering water and energy budgets at a reach scale considerably improves model performances with respect to non-advective models. Because reach size can be arbitrarily tuned, SESTET is capable of providing stream temperature estimates at high spatial resolution.

It is worthwhile to recall that traditional, non-advective models are typically applied to given cross-sections of a river, with the result that the estimated values of parameters characterizing the air-water heat exchange reflect local conditions (e.g. morphological features, riparian shading, wind velocity). Hence, the variability of these parameters across a river network hinders one from applying such models to predict stream temperatures in ungauged reaches.

$\therefore$, we argue that part of such variability is to be attributed to the role of advective heat fluxes. By explicitly accounting for these heat fluxes in the formulation of the stream temperature model, we showed that it is possible to increase the reliability in the use of spatially constant parameters expressing the relationship between equilibrium stream temperature and air temperatures and the heat exchange velocity, thereby enabling the estimation of spatial patterns of stream temperature across a river.

At small (daily) time scales as in the case here explored, the correct evaluation of air temperature fields across the region is crucial to the production of reliable stream temperature estimates. The sole use of a lapse rate would not take into account the phenomenon of temperature inversion, which may heavily characterize the climate in the portions of the watershed at higher elevation. Therefore, distributed air temperature measuring stations are needed, and the spatial interpolation approach should be as much close to the data as possible.

The SESTET models relies on a number of simplifying assumptions, mainly with regards to the hydraulic charac- 
terization of the river network. In particular, the assumption of large rectangular river's cross-sections appears fair for the case study river Wigger, which is a highly anthropized river, with banks often stabilized by means of boulders and streambed characterized by a series of check dams. Nevertheless, we deem that such assumption could be possibly adopted for several other river systems of comparable size if the model is run at daily time scale. In fact, it has been observed [Toffolon and Piccolroaz, 2015] that in relatively small streams (say, of total contributing area up to $10^{3} \mathrm{~km}^{2}$ ) the time scale for the adaptation of water temperature to the external forcing is much shorter than one day, and hence a precise estimation of water depths becomes irrelevant to a good model fitting.

Future developments should entail extensive testing of our model on other catchments, possibly characterized by different hydromorphological features with respect to the case study here analyzed, such as higher elevation gradients and/or hydrological regimes governed by snowmelt or presence of dams. Another interesting application would consist in applying SESTET at finer time scales (e.g., hourly), in a bid to reproduce diel variations in stream temperature. Indeed, our model can readily be run at hourly scale, although some of the assumptions here formulated, especially with regards to the equilibrium stream temperature and the hydraulic characterization of the river will require further care. 


\section{References}

Allan, J. D. and Castillo, M. M. (2007). Stream ecology: structure and function of running waters. Springer Science \& Business Media.

Angilletta, M. J., Niewiarowski, P. H., and Navas, C. A. (2002). The evolution of thermal physiology in ectotherms. Journal of Thermal Biology, 27(4):249-268.

Arismendi, I., Safeeq, M., Dunham, J. B., and Johnson, S. L. (2014). Can air temperature be used to project influences of climate change on stream temperature? Environmental Research Letters, 9(8).

Armstrong, J., Kemp, P., Kennedy, G., Ladle, M., and Milner, N. (2003). Habitat requirements of Atlantic salmon and brown trout in rivers and streams. Fisheries Research, 62(2):143-170.

Arora, R., Toffolon, M., Tockner, K., and Venohr, M. (2018). Thermal discontinuities along a lowland river: The importance of urban areas and lakes. Journal of Hydrology, 564:811-823.

Arrigoni, A. S., Poole, G. C., Mertes, L. A., O’Daniel, S. J., Woessner, W. W., and Thomas, S. A. (2008). Buffered, lagged, or cooled? Disentangling hyporheic influences on temperature cycles in stream channels. Water Resources Research, 44(9).

Barry, R. G. and Chorley, R. J. (2009). Atmosphere, weather and climate. Routledge, London.

Benyahya, L., Caissie, D., St-Hilaire, A., Ouarda, T. B. M. J., and Bobée, B. (2007). A review of statistical water temperature models. Canadian Water Resources Journal, 32(3):179-192.

Berman, C. and Quinn, T. (1991). Behavioural thermoregulation and homing by spring chinook salmon, Oncorhynchus tshawytscha (Walbaum), in the Yakima River. Journal of Fish Biology, 39(3):301-312.

Bustillo, V., Moatar, F., Ducharne, A., Thiéry, D., and Poirel, A. (2014). A multimodel comparison for assessing water temperatures under changing climate conditions via the equilibrium temperature concept: Case study of the Middle jire River, France. Hydrological Processes, 28(3):1507-1524.

Caissie, D. (2006). The thermal regime of rivers: A review. Freshwater Biology, 51(8):1389-1406.

Caissie, D., El-Jabi, N., and Satish, M. G. (2001). Modelling of maximum daily water temperatures in a small stream using air temperatures. Journal of Hydrology, 251(1-2):14-28.

Caissie, D., Satish, M. G., and El-Jabi, N. (2005). Predicting river water temperatures using the equilibrium temperature concept with application on Miramichi River catchments (New Brunswick, Canada). Hydrological Processes, 19(11):2137-2159.

Cao, Q., Sun, N., Yearsley, J., Nijssen, B., and Lettenmaier, D. P. (2016). Climate and land cover effects on the temperature of Puget Sound streams. Hydrological Processes, 30(13):2286-2304. 
Carraro, L., Bertuzzo, E., Mari, L., Fontes, I., Hartikainen, H., Strepparava, N., Schmidt-Posthaus, H., Wahli, T., Jokela, J., Gatto, M., and Rinaldo, A. (2017). Integrated field, laboratory, and theoretical study of PKD spread in a Swiss prealpine river. Proceedings of the National Academy of Sciences of the United States of America, 114(45):11992-11997.

Comola, F., Schaefli, B., Rinaldo, A., and Lehning, M. (2015). Thermodynamics in the hydrologic response: Travel time formulation and application to alpine catchments. Water Resources Research, 51(3):1671-1687.

Cornes, R. C., van der Schrier, G., van den Besselaar, E. J., and Jones, P. D. (2018). An Ensemble Version of the E-OBS Temperature and Precipitation Data Sets. Journal of Geophysical Research: Atmospheres, 123(17):9391-9409.

Csanady, G. T. (1974). Equilibrium theory of the planetary boundary layer with an inversion lid. Boundary-Layer Meteorology, 6(1-2):63-79.

Demars, B. O. L., Russell Manson, J., Ólafsson, J. S., Gíslason, G. M., Gudmundsdóttir, R., Woodward, G., Reiss, J., Pichler, D. E., Rasmussen, J. J., and Friberg, N. (2011). Temperature and the metabolic balance of streams. Freshwater Biology, 56(6):1106-1121.

Dodson, R. and Marks, D. (1997). Daily air temperature interpolated at high spatial resolution over a large mountainous region. Climate Research, 8(1):1-20.

Ducharne, A. (2008). Importance of stream temperature to climate change impact on water quality. Hydrology and Earth System Sciences, 12(3):797-810.

Dugdale, S. J., Hannah, D. M., and Malcolm, I. A. (2017). River temperature modelling: A review of process-based approaches and future directions. Earth-Science Reviews, 175:97-113.

Eaton, J. G., McCormick, J., Stefan, H. G., and Hondzo, M. (1995). Extreme value analysis of a fish/temperature field database. Ecological Engineering, 4(4):289 - 305.

Ebersole, J. L., Liss, W. J., and Frissell, C. A. (2001). Relationship between stream temperature, thermal refugia and rainbow trout Oncorhynchus mykiss abundance in arid-land streams in the northwestern United States. Ecology of reshwater Fish, 10(1):1-10.

Edinger, J. E., Duttweiler, D. W., and Geyer, J. C. (1968). The response of water temperatures to meteorological conditions. Water Resources Research, 4(5):1137-1143.

Evans, E.C., McGregor, G.R., and Petts, G.E., (1998). River energy budgets with special reference to river bed processes. Hydrological Processes, 12:575-595.

Gallice, A., Schaefli, B., Lehning, M., Parlange, M. B., and Huwald, H. (2015). Stream temperature prediction in ungauged basins: Review of recent approaches and description of a new physics-derived statistical model. Hydrology and Earth System Sciences, 19(9):3727-3753.

Gelman, A., Carlin, J. B., Stern, H. S., and Rubin, D. B. (2004). Bayesian data analysis. Chapman and Hall/CRC. 
Haario, H., Saksman, E., and Tamminen, J. (2001). An adaptive metropolis algorithm. Bernoulli, 7(2):223-242.

Hari, R. E., Livingstone, D. M., Siber, R., Burkhardt-Holm, P., and Güttinger, H. (2006). Consequences of climatic change for water temperature and brown trout populations in alpine rivers and streams. Global Change Biology, 12(1):10-26.

Hastie, T., Tibshirani, R., and Friedman, J. (2001). The Elements of Statistical Learning. Springer Series in Statistics. Springer New York Inc., New York, NY, USA.

Heggenes, J. (1990). Habitat utilization and preferences in juvenile Atlantic salmon (Salmo salar) in streams. River Research and Applications, 5(4):341-354.

Heggenes, J., Baglinière, J. L., and Cunjak, R. A. (1999). Spatial niche variability for young Atlantic salmon (Salmo salar) and brown trout (S. trutta) in heterogeneous streams. Ecology of Freshwater Fish, 8(1):1-21.

Jarvis, C. H. and Stuart, N. (2001). A comparison among strategies for interpolating maximum and minimum daily air temperatures. Part II: Interaction between number of guiding variables and the type of interpolation method. Journal of Applied Meteorology, 40(6):1075-1084.

Jonsson, B. and Jonsson, N. (2009). A review of the likely effects of climate change on anadromous Atlantic salmon Salmo salar and brown trout Salmo trutta, with particular reference to water temperature and flow. Journal of Fish Biology, 75(10):2381-2447.

Kennedy, J. and Eberhart, R. (1995). Particle swarm optimization. In IEEE International Conference on Neural Networks Conference Proceedings, volume 4, pages 1942-1948.

Lee, R. M. and Rinne, J. N. (1980). Critical thermal maxima of five trout species in the southwestern United States. Transactions of the American Fisheries Society, 109(6):632-635.

Leopold, L. and Maddock, T. (1953). The hydraulic geometry of stream channels and some physiographic implications. Report Geological Survey Professional Paper 252, Washington DC.

Matthews, W. J. and Zimmerman, E. G. (1990). Potential effects of global warming on native fishes of the southern Great Plains and the Southwest. Fisheries, 15(6):26-32.

McCullough, D. A., Bartholow, J. M., Jager, H. I., Beschta, R. L., Cheslak, E. F., Deas, M. L., Ebersole, J. L., Foott, J. S., Johnson, S. L., Marine, K. R., Mesa, M. G., Petersen, J. H., Souchon, Y., Tiffan, K. F., and Wurtsbaugh, W. A. (2009). Research in thermal biology: Burning questions for coldwater stream fishes. Reviews in Fisheries Science, 17(1):90-115.

Morse, W. L. (1970). Stream temperature prediction model. Water Resources Research, 6(1):290-302.

Myers, D. E. (1994). Spatial interpolation: an overview. Geoderma, 62(1-3):17-28.

Nielsen, J. L., Lisle, T. E., and Ozaki, V. (1994). Thermally stratified pools and their use by steelhead in Northern California streams. Transactions of the American Fisheries Society, 123(4):613-626. 
Okamura, B., Hartikainen, H., Schmidt-Posthaus, H., and Wahli, T. (2011). Life cycle complexity, environmental change and the emerging status of salmonid proliferative kidney disease. Freshwater Biology, 56(4):735-753.

Parmesan, C. and Yohe, G. (2003). A globally coherent fingerprint of climate change impacts across natural systems. Nature, 421(6918):37-42.

Piccolroaz, S., Calamita, E., Majone, B., Gallice, A., Siviglia, A., and Toffolon, M. (2016). Prediction of river water temperature: a comparison between a new family of hybrid models and statistical approaches. Hydrological Processes, 30(21):3901-3917.

Rodriguez-Iturbe, I. and Rinaldo, A. (2001). Fractal River Basins. Chance and self-organization. Cambridge University Press, New York, US.

Sedell, J. R., Reeves, G. H., Hauer, F. R., Stanford, J. A., and Hawkins, C. P. (1990). Role of refugia in recovery from disturbances: Modern fragmented and disconnected river systems. Environmental Management, 14(5):711-724.

Sinokrot, B. A. and Stefan, H. G. (1993). Stream temperature dynamics: measurements and modeling. Water Resources Research, 29(7):2299-2312.

Smith, K. (1972). River water temperatures - an environmental review. Scottish Geographical Magazine, 88(3):211-220.

Spiegelhalter, D. J., Best, N. G., Carlin, B. P., and Van Der Linde, A. (2002). Bayesian measures of model complexity and fit. Journal of the Royal Statistical Society.Series B: Statistical Methodology, 64(4):583-616.

Stahl, K., Moore, R. D., Floyer, J. A., Asplin, M. G., and McKendry, I. G. (2006). Comparison of approaches for spatial interpolation of daily air temperature in a large region with complex topography and highly variable station density. Agricultural and Forest Meteorology, 139(3-4):224-236.

Sverdrup, H. U., Johnson, M. W., and Fleming, R. H. (1942). The Oceans: Their physics, chemistry, and general biology Prentice-Hall, New York, Vol. 7.

Tarboton, D. G., Bras, R. L., and Rodriguez-Iturbe, I. (1991). On the extraction of channel networks from digital evation data. Hydrological Processes, 5(1):81-100.

Theurer, F. D., Lines, I., and Nelson, T. (1985). Interaction between riparian vegetation, water temperature, and salmonid habitat in the Tucannon River. JAWRA Journal of the American Water Resources Association, 21(1):53-64.

Thornton, P. E., Running, S. W., and White, M. A. (1997). Generating surfaces of daily meteorological variables over large regions of complex terrain. Journal of Hydrology, 190(3-4):214-251.

Toffolon, M. and Piccolroaz, S. (2015). A hybrid model for river water temperature as a function of air temperature and discharge. Environmental Research Letters, 10(11). 114011.

Torgersen, C. E., Price, D. M., Li, H. W., and McIntosh, B. A. (1999). Multiscale thermal refugia and stream habitat associations of chinook salmon in Northeastern Oregon. Ecological Applications, 9(1):301-319. 
Webb, B. W., Hannah, D. M., Moore, R. D., Brown, L. E., and Nobilis, F. (2008). Recent advances in stream and river temperature research. Hydrological Processes, 22(7):902-918.

Yvon-Durocher, G., Jones, J. I., Trimmer, M., Woodward, G., and Montoya, J. M. (2010). Warming alters the metabolic balance of ecosystems. Philosophical Transactions of the Royal Society B: Biological Sciences, 365(1549):2117-2126. 

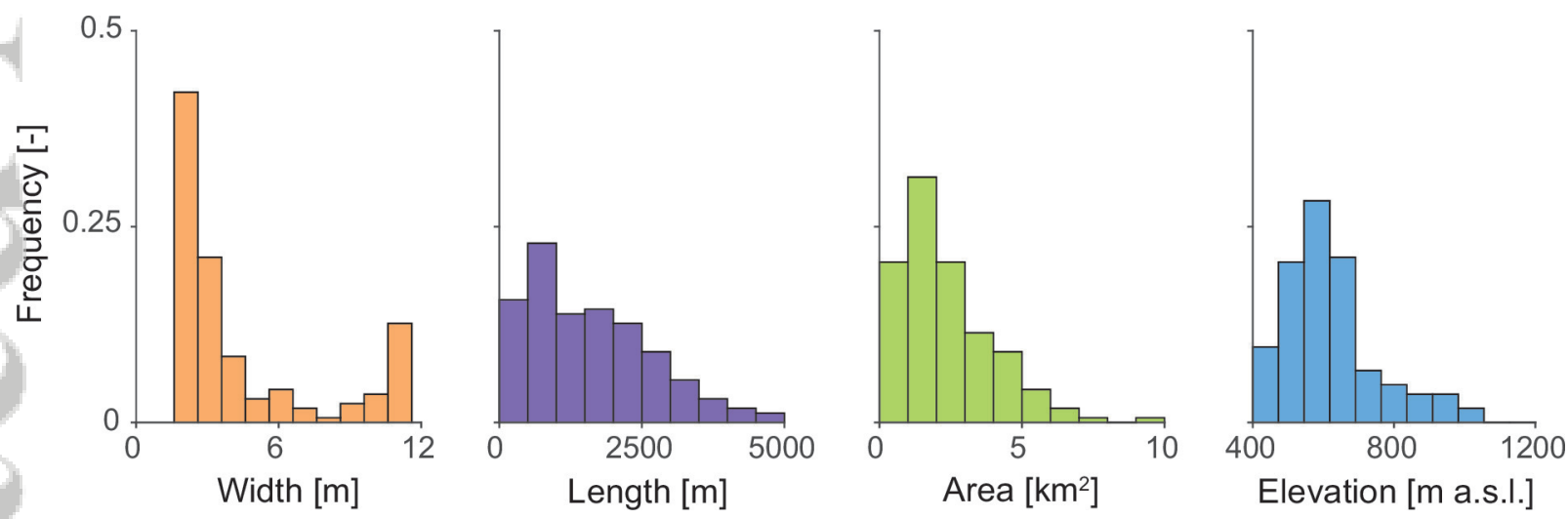

carraro2019_figs1.eps 


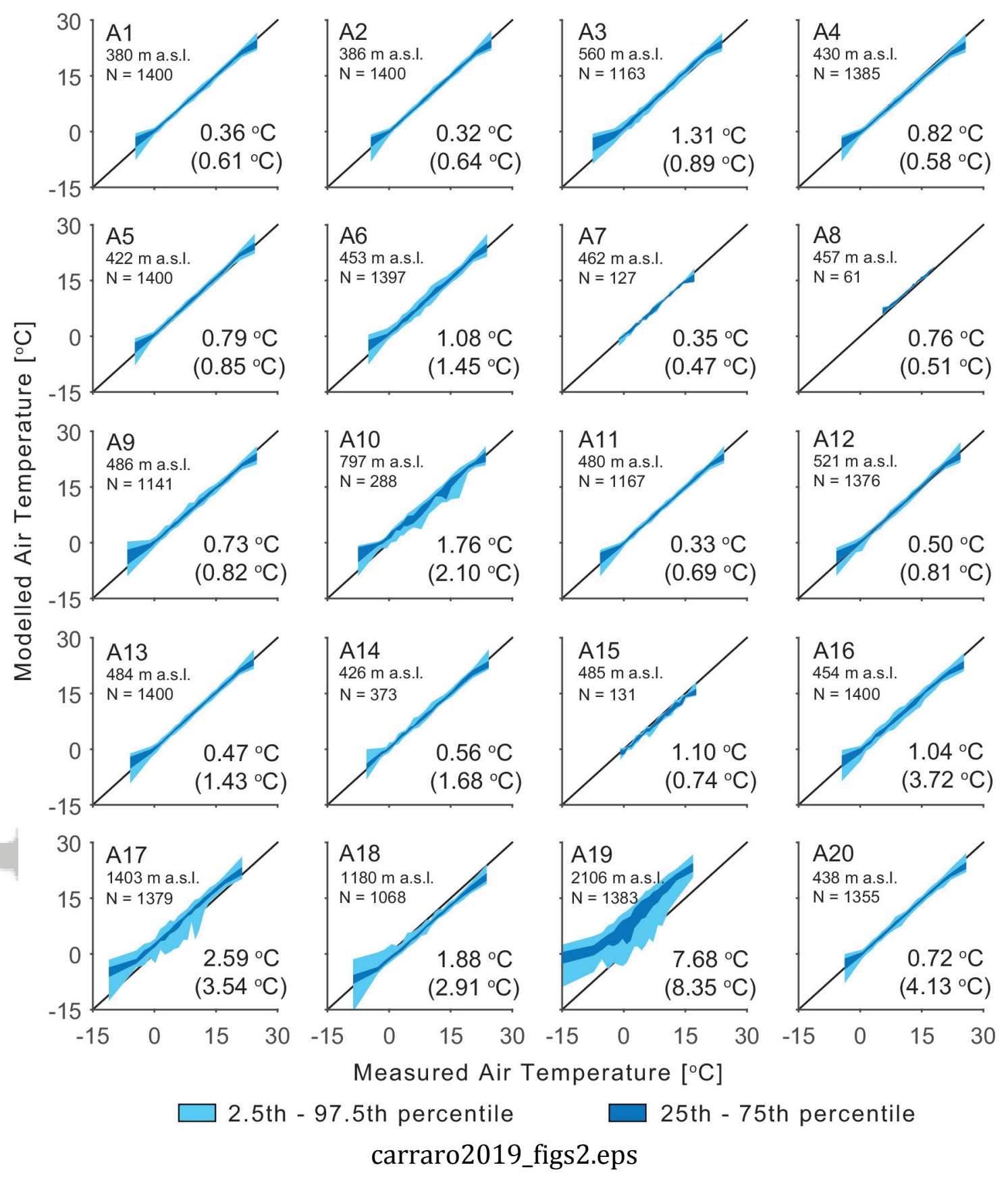

This article is protected by copyright. All rights reserved. 

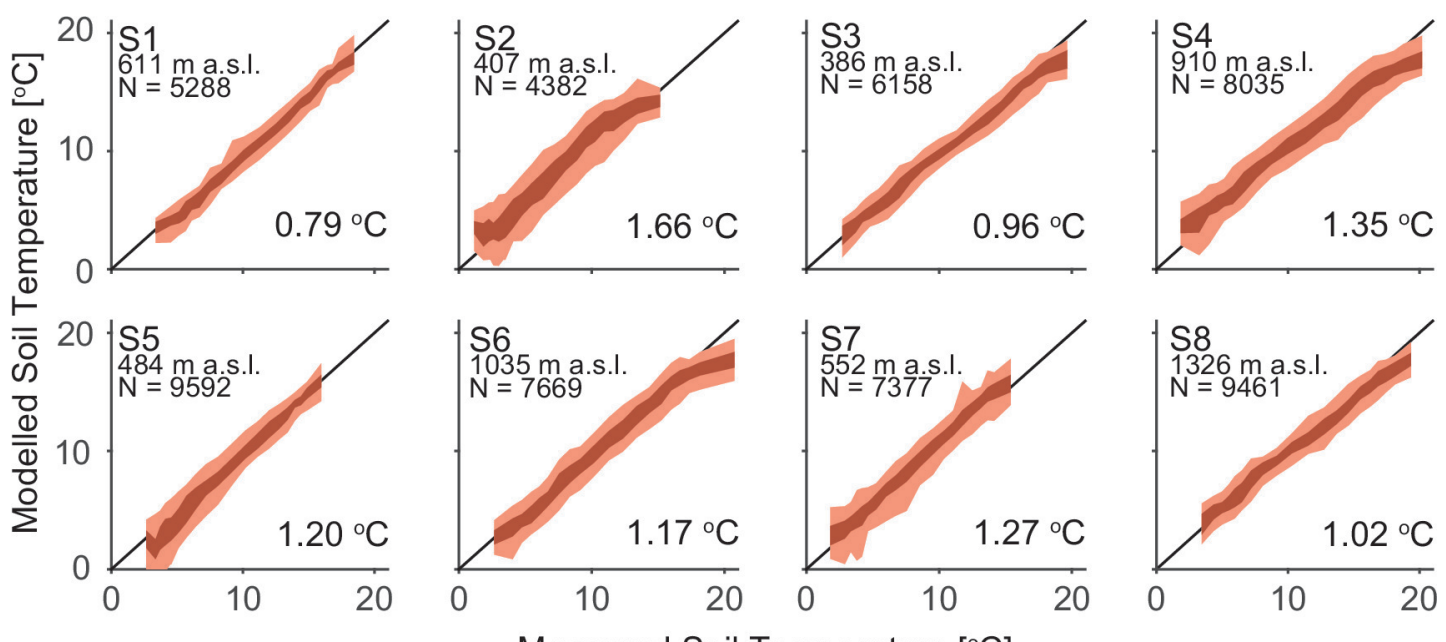

Measured Soil Temperature $\left[{ }^{\circ} \mathrm{C}\right]$

$\square$ 2.5th - 97.5th percentile

$\square$ 25th - 75th percentile

carraro2019_figs3.eps 


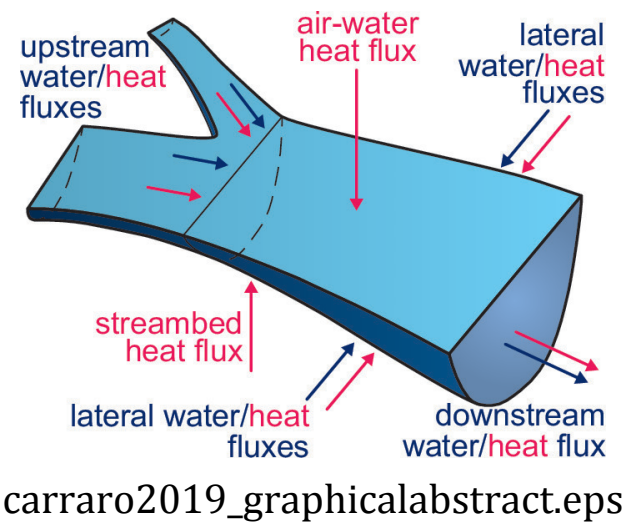

This article is protected by copyright. All rights reserved. 


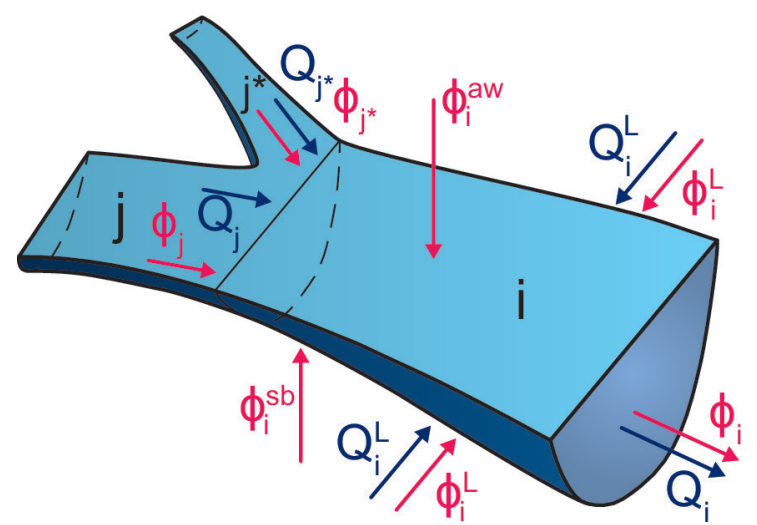

fig1.eps

This article is protected by copyright. All rights reserved. 
a)
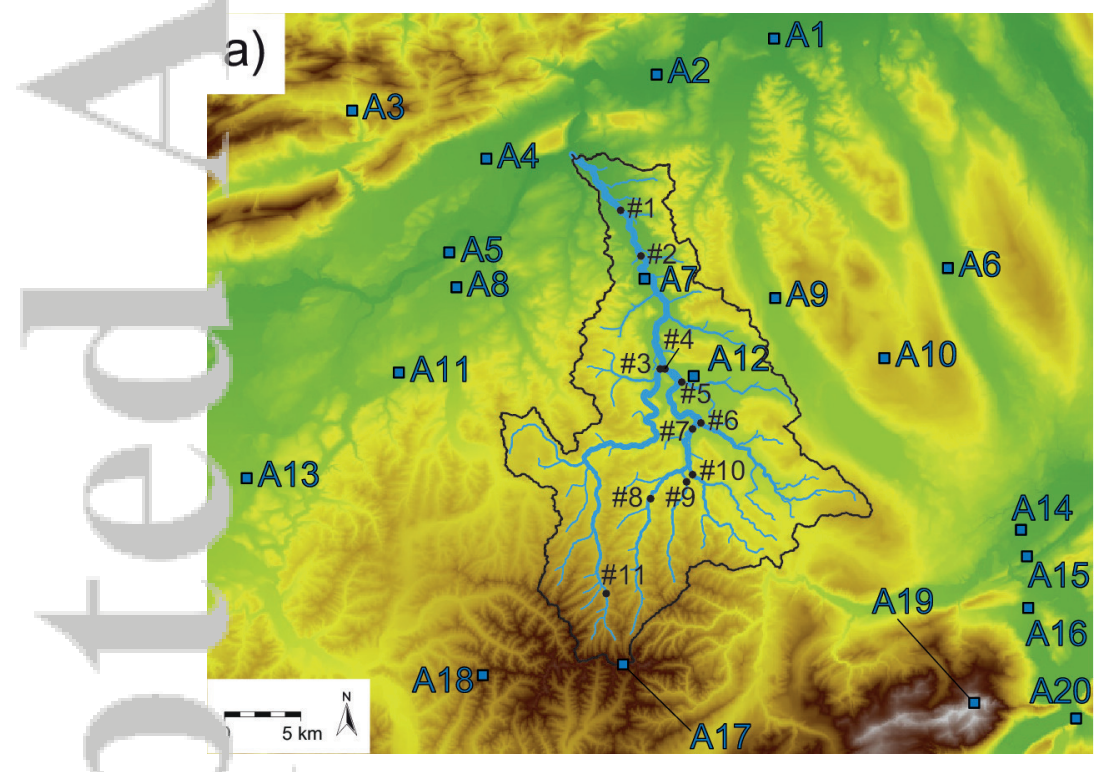

fig2.eps

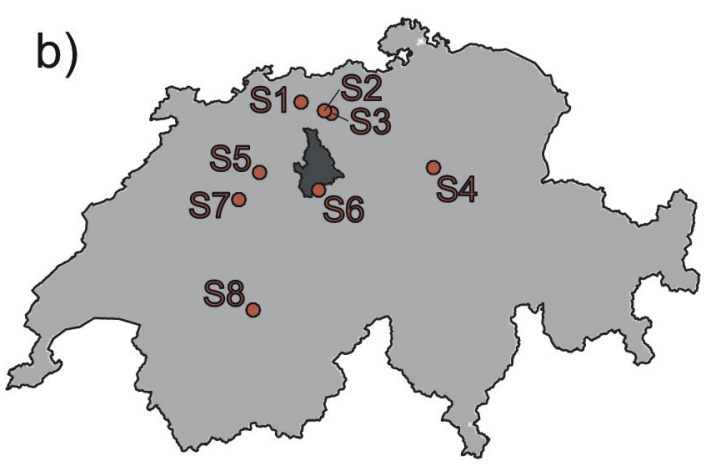

- Water temperature gauge

$\square$ Air temperature station

- Soil temperature station

$\begin{array}{llllll}0 & 400 & 800 & 1200 & 1600 & 2000\end{array}$

Elevation [m a.s.I.] 
Model

RMSE
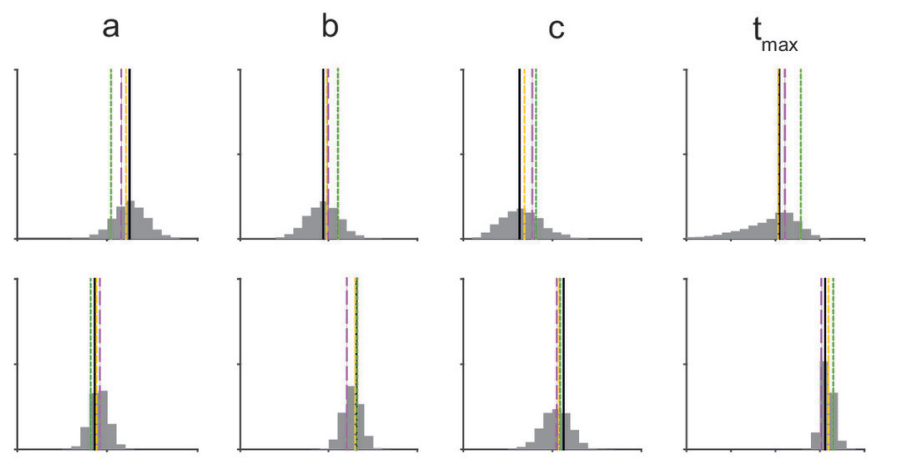

$\mathrm{k}(\hat{\mathrm{k}})$

$\delta$

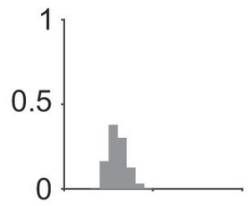

1

L $\quad 0.5$.

गे
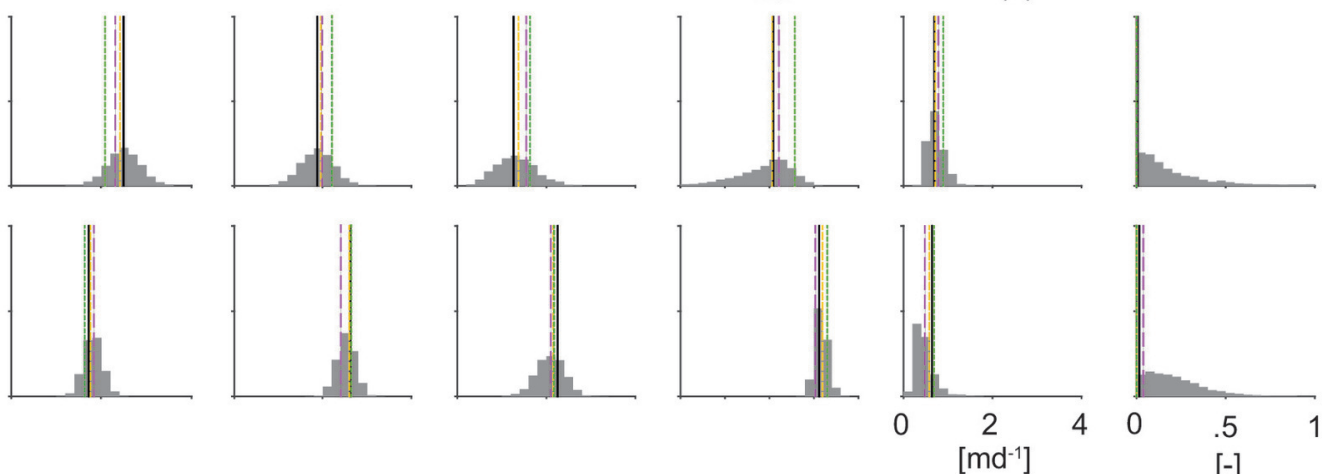

F 1
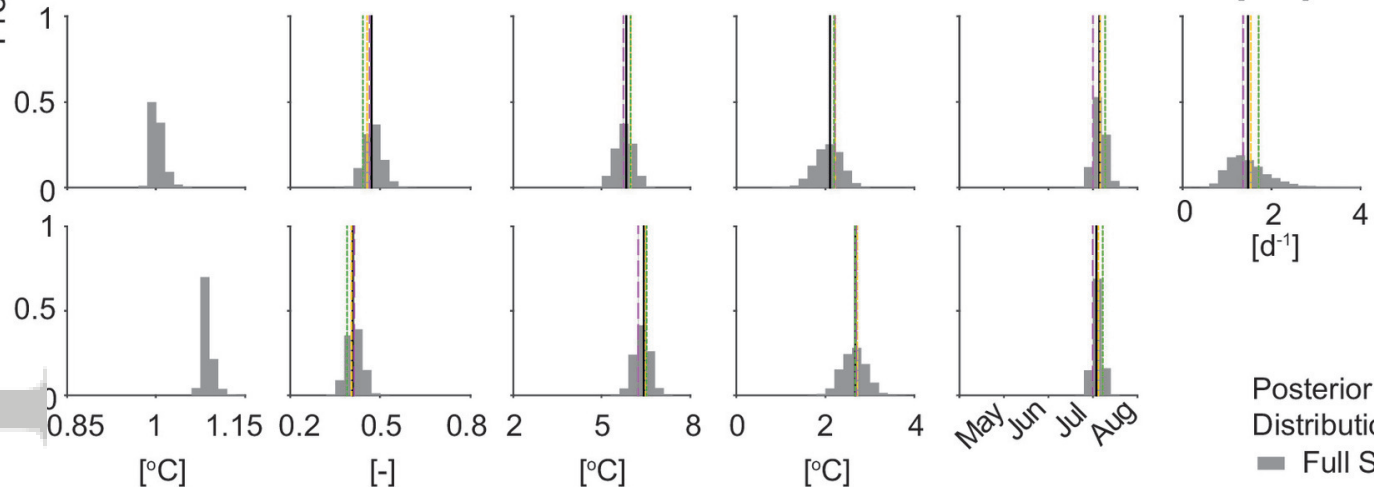

$\left[\mathrm{d}^{-1}\right]$

Best Fit

Parameters

- Full Set

Posterior - Subset I

Distribution -- Subset II

- Full Set -... Subset III

fig3.eps 

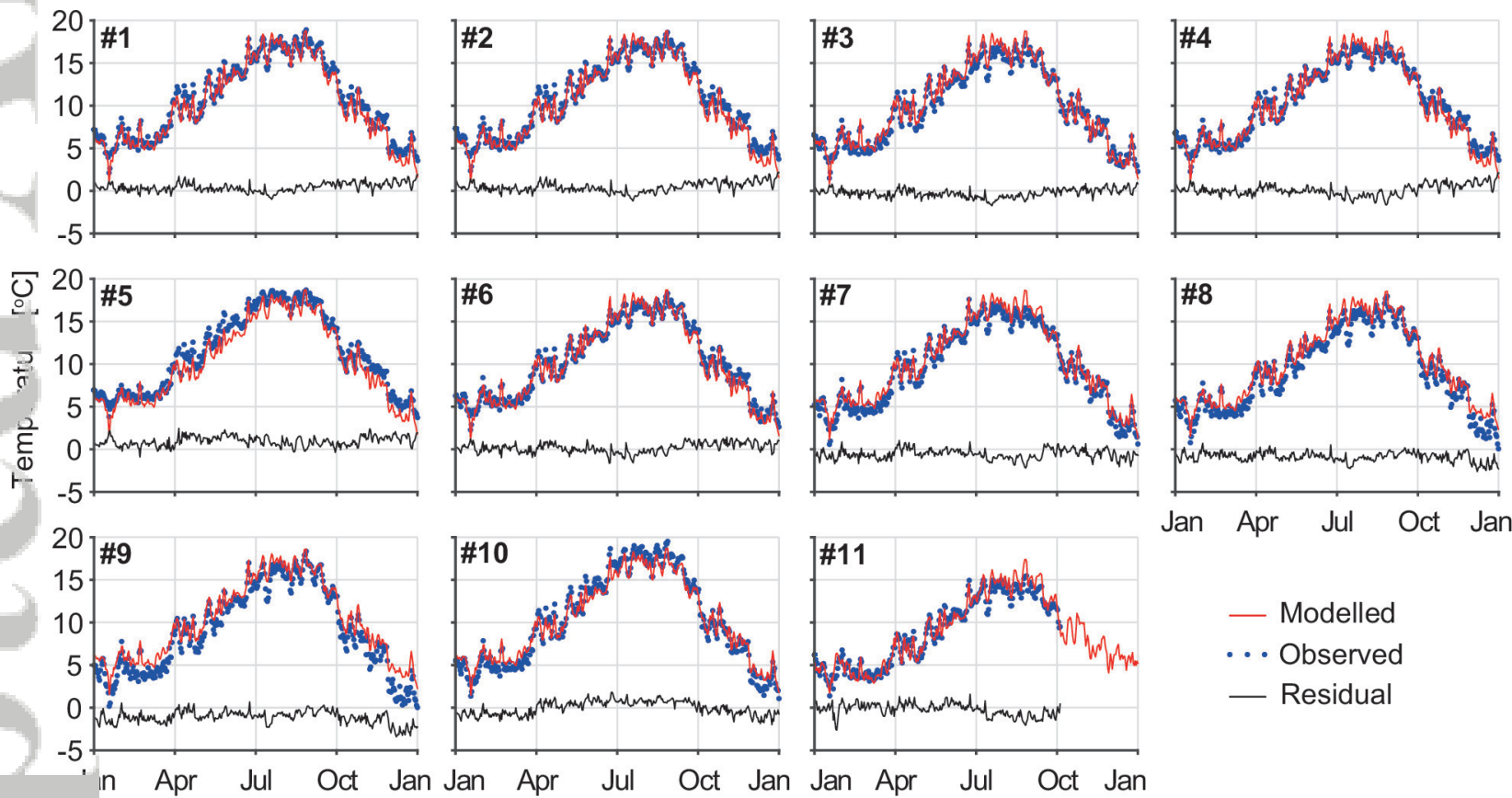

fig4.eps 

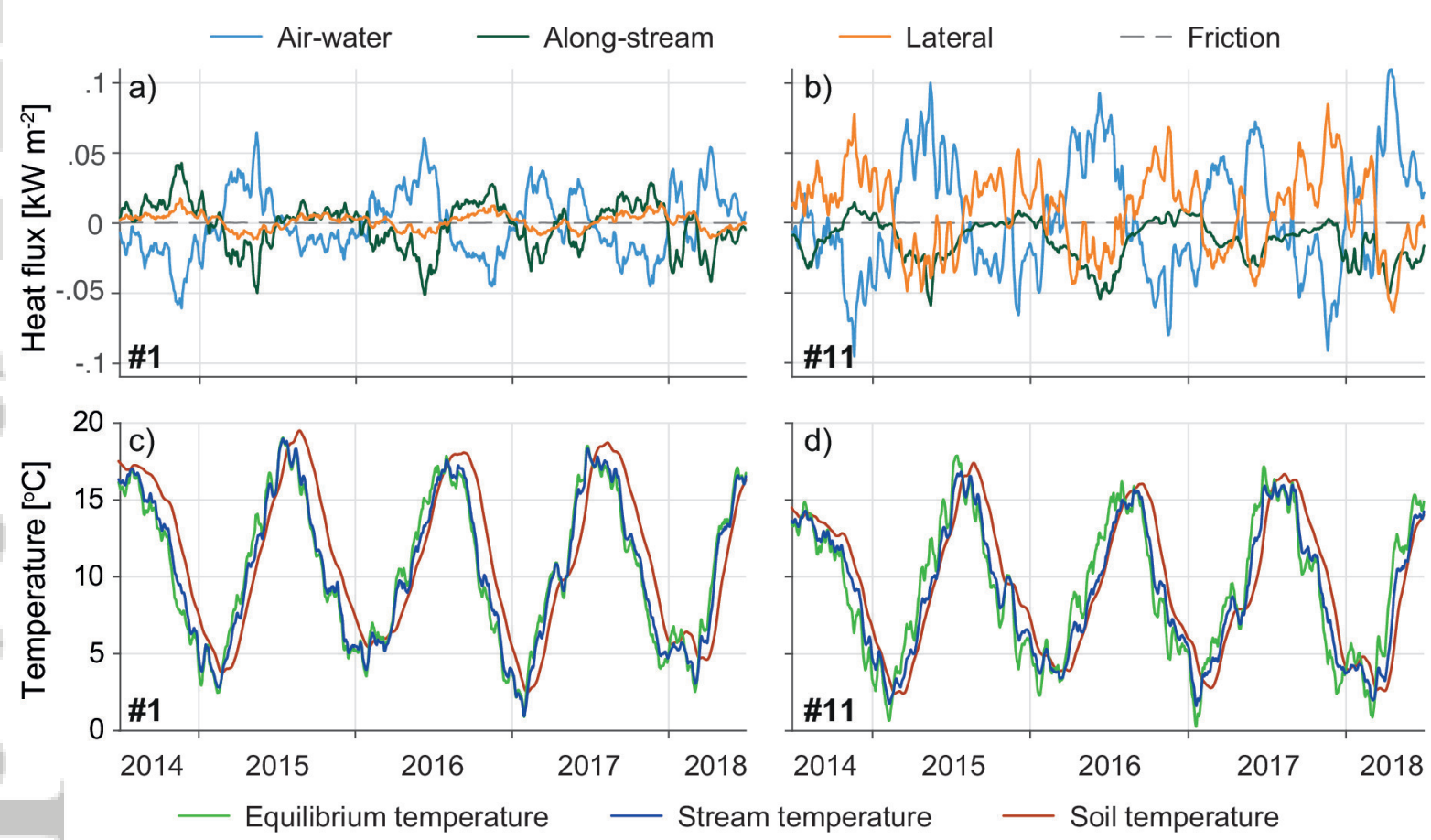

fig5.eps 


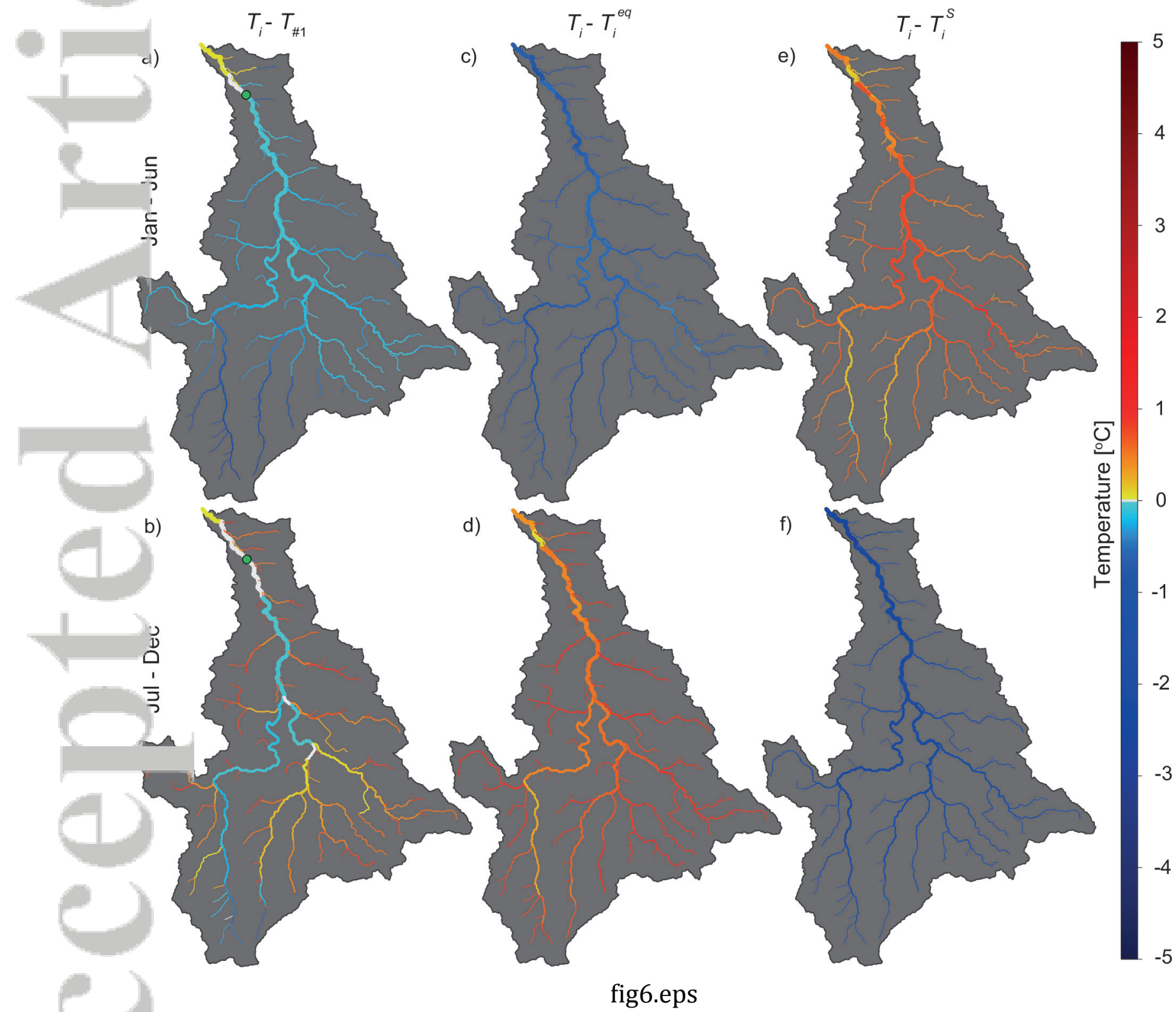



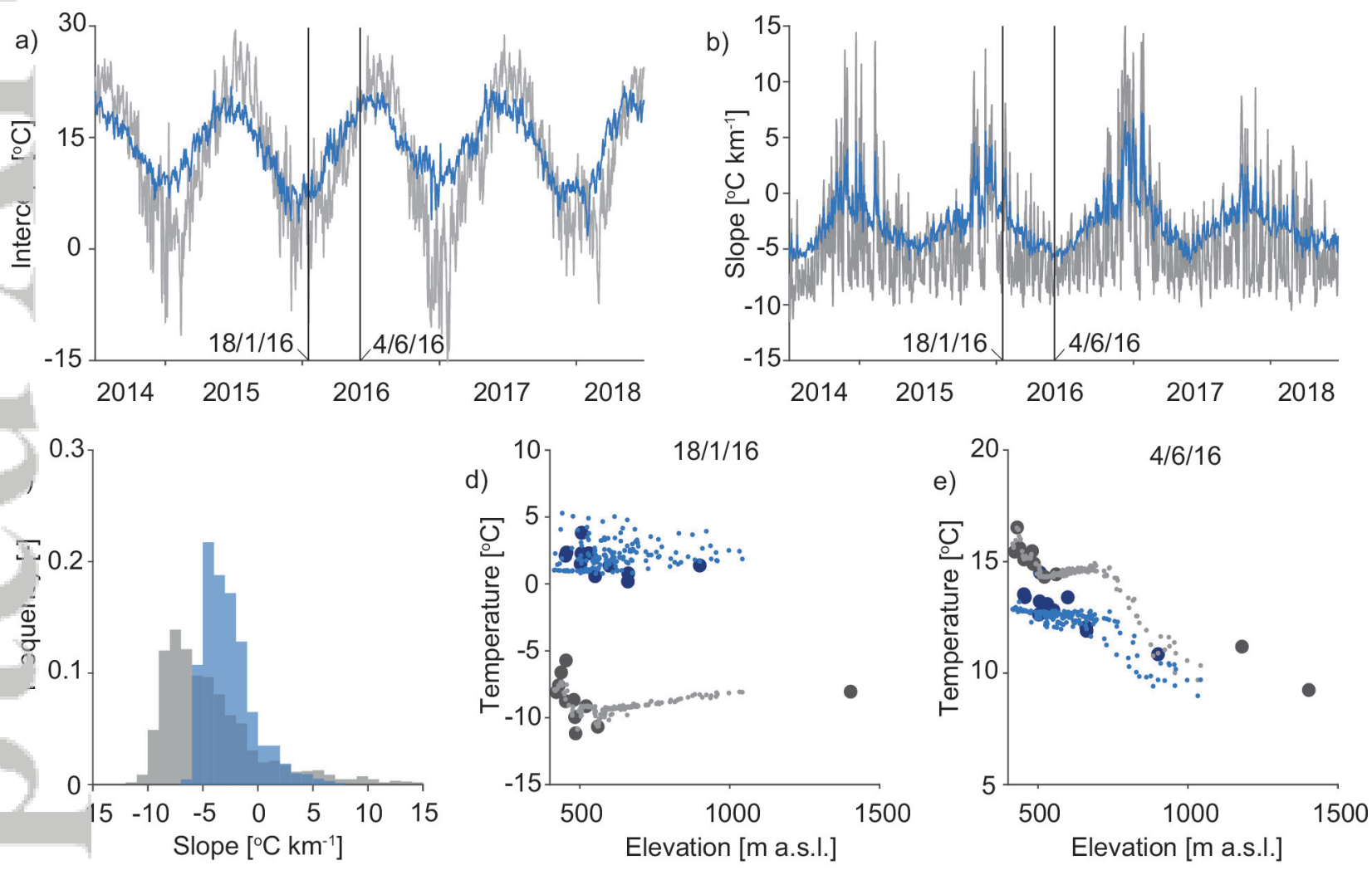

$\ldots$ Water temperatures (modelled) $\quad \ldots$.... Air temperatures (interpolated)

- Water temperatures (measured) $\bullet$ Air temperatures (measured)

fig7.eps 